\title{
PERDAS DE SOLO E DE ÁGUA EM DIFERENTES SISTEMAS DE CAPTAÇÃO IN SITU NO SEMI-ÁRIDO BRASILEIRO ${ }^{1}$
}

\author{
LUIZA T. L. BRITO ${ }^{2}$, NILTON B. CAVALCANTI ${ }^{3}$, JOSÉ B. DOS ANJOS ${ }^{4}$, \\ ADERALDO S. SILVA ${ }^{4}$, LÚCIO A. PEREIRA ${ }^{5}$
}

\begin{abstract}
RESUMO: Os sistemas de cultivo utilizados no semi-árido brasileiro apresentam riscos de perda devido à irregularidade das chuvas, devendo-se associá-los a práticas que propiciem maior infiltração e, conseqüentemente, menor erosão, o que pode ser obtido por meio de técnicas de captação de água de chuva in situ. Neste trabalho, teve-se o objetivo de avaliar as perdas de água e de solo em área cultivada com milho (Zea mays L.), submetida a diferentes sistemas de preparo do solo, correspondendo aos tratamentos Guimarães Duque (T1); aração profunda (T2); aração parcial (T3) e sulcos barrados (T4), comparados com o sistema tradicional (T5), que corresponde ao plantio sem preparo do solo. Após cada evento de chuva, a água e o solo escoados foram coletados e medidos. A umidade do solo em diferentes profundidades foi monitorada durante o ciclo de produção da cultura e avaliada a produtividade dos grãos por meio da análise de variância. A partir dos resultados, pode-se observar que o método Guimarães Duque (T1) proporcionou maiores perdas de água $(6.696 \mathrm{~L})$ e de solo $\left(15.225 \mathrm{~kg} \mathrm{ha}^{-1}\right)$, enquanto as menores perdas foram obtidas com os sulcos barrados (T4), correspondendo a $1.066 \mathrm{~L}$ e $1.022 \mathrm{~kg} \mathrm{ha}^{-1}$, respectivamente. Nesse tratamento (T4), também foi obtida a maior produtividade de grãos (606 $\mathrm{kg} \mathrm{ha}^{-1}$ ), apresentando-se como o sistema mais indicado para as condições analisadas.
\end{abstract}

PALAVRAS-CHAVE: erosão, escoamento, chuva, Zea mays L.

\section{SOIL AND WATER LOSSES IN SITU WATER HARVESTING SYSTEMS IN THE BRAZILIAN SEMI-ARID}

\begin{abstract}
The cropping systems used in the Brazilian semi-arid show risks of losses due to irregularity of rainfall, requiring the use of practices which produce higher water infiltration and, as a consequence, lower soil erosion, which can be obtained through in situ rainwater harvest techniques. This study had the objective of evaluating soil and water losses in a corn (Zea mays L.) area subjected to different soil preparation systems: Guimarães Duque (T1), deep plowing (T2), partial plowing (T3), and furrows with barriers (T4), compared to the traditional system (T5), i.e., plain planting. After each rainfall, the drained water and soil were collected and measured. The soil moisture at different depths was monitored during the crop cycle and grain yield was evaluated through analysis of variance. The results allowed to conclude that $\mathrm{T} 1$ showed the biggest water $(6,696 \mathrm{~L})$ and soil $\left(15,225 \mathrm{~kg} \mathrm{ha}^{-1}\right)$ losses, while the smallest losses occurred with $\mathrm{T} 4$ (1,066 L and $1,022 \mathrm{~kg} \mathrm{ha}^{-1}$, respectively). The highest grain yield (606 $\left.\mathrm{kg} \mathrm{ha}^{-1}\right)$ was obtained in $\mathrm{T} 4$, which allows indicating it as the most promising system for the Brazilian semi-arid conditions.
\end{abstract}

KEYWORDS: erosion, runoff, rain, Zea mays L.

\footnotetext{
${ }^{1}$ Pesquisa Financiada pelo CNPq/CT-HIDRO (Processo n ${ }^{0}$ 504.112/03-1).

${ }^{2}$ Eng $^{\mathrm{a}}$ Agrícola, Pesquisadora, Embrapa Semi-Árido, Petrolina - PE, Fone: (0XX87) 3862-1711, luizatlb@cpatsa.embrapa.br

${ }^{3}$ Administrador de Empresas, Embrapa Semi-Árido, Petrolina - PE.

${ }^{4}$ Eng $^{\mathrm{O}}$ Agrônomo, Pesquisador, Embrapa Semi-Árido, Petrolina - PE.

${ }^{5}$ Ecólogo, Pesquisador, Embrapa Semi-Árido, Petrolina - PE.

Recebido pelo Conselho Editorial em: 19-9-2007
}

Aprovado pelo Conselho Editorial em: 30-9-2008 


\section{INTRODUÇÃO}

A erosão constitui-se em um dos principais fatores de degradação das características do solo, causada principalmente pela exploração intensiva, associada às inadequadas práticas de manejo e de conservação utilizadas na atividade agrícola. A desagregação e o transporte das partículas de solo estão diretamente relacionados à intensidade e à duração da chuva, à resistência do material de origem e à declividade da superfície do solo. $\mathrm{O}$ grau com que o solo resiste às forças de impacto da chuva e ao escoamento é fator determinante na estimativa das perdas de solo (BERTONI \& LOMBARDI NETO, 1999).

As características edafoclimáticas do semi-árido brasileiro apresentam regime de precipitação pluviométrica irregular no tempo e no espaço, cujas chuvas ocorrem em até quatro meses em diversos municípios, elevadas taxas evapotranspirométricas, solos rasos, baixas fertilidade e capacidade de retenção de água, além de outros fatores de ordem estrutural e socioeconômica, tornando a agricultura dependente de chuva uma atividade de risco, com conseqüências graves para a sobrevivência das famílias dos agricultores. Segundo PORTO et al. (1983), apenas três em cada dez anos são considerados normais quanto à distribuição das chuvas no semi-árido. Nesse sentido, a Embrapa Semi-Árido, desde sua criação, em meados da década de 1970, empreendeu esforços na valorização da água de chuva, desenvolvendo e/ou adaptando tecnologias visando a aumentar a disponibilidade de água para o consumo humano e a reduzir esses riscos da exploração agropecuária.

No contexto dos sistemas agrícolas praticados, prevalece o método tradicional de cultivo mínimo, que utiliza a enxada manual com a semeadura em covas, dando origem a uma pequena depressão, que é capaz de armazenar água da chuva na própria cova. Esse sistema é aparentemente pouco agressivo ao meio ambiente, mas, como o solo não foi preparado (arado), a sua superfície se apresenta ligeiramente compactada, dificultando a infiltração da água e facilitando o escoamento superficial, que contribui para o processo erosivo. Portanto, técnicas de preparo do solo, como a captação in situ, são as mais recomendáveis, uma vez que, além de aumentar a disponibilidade de água para as plantas, conserva o solo e os fertilizantes no próprio local de plantio (SILVA \& PORTO, 1982; ANJOS et al., 2000).

A captação de água de chuva pode ser incrementada a partir de métodos de preparo do solo para o plantio de culturas como milho, feijão e mandioca. Entre os métodos mais utilizados, podemse citar o Guimarães Duque, os sulcos barrados e a aração total e parcial.

Visando a reduzir ainda mais os riscos de exploração agrícola no semi-árido brasileiro, os métodos de captação de água de chuva in situ podem ser associados a culturas com características mais adaptadas às condições climáticas, como, por exemplo, culturas com ciclo produtivo precoce, resistentes à seca, entre outras. Assim, este trabalho teve por objetivo avaliar as perdas de água de chuva ocorridas em área explorada com a cultura do milho (Zea mays L.), sob diferentes métodos de preparo do solo.

\section{MATERIAL E MÉTODOS}

A pesquisa foi realizada na Estação Experimental da Caatinga, pertencente à Embrapa SemiÁrido, município de Petrolina - PE, no período de fevereiro a maio de 2006. O clima da região é classificado como semi-árido quente (BSw'h), conforme classificação de Köeppen, sendo as coordenadas geográficas $09^{\circ} 09^{\prime}$ de latitude $\mathrm{S}$ e $40^{\circ} 22^{\prime}$ ' de longitude $\mathrm{W}$, e a altitude de $365 \mathrm{~m}$. A precipitação média anual é de 566,7 mm, obtida a partir da série de dados do período de 1964-2003 (MOURA et al., 2005). O solo da área experimental é classificado como Argissolo Amarelo eutrófico abrúptico plíntico (SANTOS et al., 2006) e apresenta características físicas especificadas na Tabela 1.

Após chuva de $27 \mathrm{~mm}$, ocorrida em 13 de fevereiro, com duração de tempo média de 35 minutos, realizou-se o preparo do solo utilizando arado com três discos e grade com 22 discos, 
ambos tracionados por força mecânica, efetuando-se o plantio no dia seguinte. $\mathrm{O}$ delineamento experimental foi inteiramente casualizado, com cinco tratamentos, constituindo-se dos diferentes métodos de preparo do solo: T1 - Guimarães Duque; T2 - aração profunda; T3 - aração parcial; T4 sulcos barrados, e T5 - sistema tradicional, que corresponde ao plantio sem preparo do solo e quatro repetições.

TABELA 1. Distribuição granulométrica, densidade da partícula e do solo e água retida em dois pontos da área experimental. Granulometric distribution, density of the particle and of soil and water retained in two points of the experimental area.

\begin{tabular}{ccccccccc}
\hline \multirow{2}{*}{ Pontos } & \multirow{2}{*}{ Prof. (m) } & \multicolumn{2}{c}{ Composição Granulométrica (\%) } & \multicolumn{2}{c}{ Densidade $\left(\mathrm{kg} \mathrm{m}^{-3}\right)$} & \multicolumn{2}{c}{ Água Retida (\%) } \\
\cline { 2 - 9 } & & Areia & Silte & Argila & Partícula & Solo & $0,33(\mathrm{~atm})$ & $15(\mathrm{~atm})$ \\
\hline \multirow{2}{*}{1} & $0-0,20$ & 81,03 & 9,54 & 9,44 & 2,58 & 1,49 & 8,06 & 4,35 \\
& $0,20-0,40$ & 73,69 & 8,75 & 17,56 & 2,56 & 1,42 & 12,37 & 7,57 \\
\hline \multirow{2}{*}{2} & $0-0,20$ & 78,85 & 13,33 & 7,82 & 2,54 & 1,43 & 11,91 & 6,84 \\
& $0,20-0,40$ & 66,94 & 7,83 & 25,23 & 2,55 & 1,34 & 12,46 & 8,61 \\
\hline
\end{tabular}

\section{Descrição dos métodos de captação de água in situ}

O método "Guimarães Duque" recebeu esse nome em homenagem ao seu idealizador e grande estudioso dos problemas da seca do Nordeste, que já utilizava essa técnica na década de 1950. Foi desenvolvido pelo INFAOL (Instituto Nordestino para o Fomento de Algodão e Oleaginosas) e adaptado pela Embrapa Semi-Árido para a exploração de cultivos anuais, principalmente milho e feijão (SILVA \& PORTO, 1982). Esse método consiste na aração do solo em faixas, a fim de que haja a formação dos sulcos, seguidos por camalhões altos e largos, confeccionados em curvas de nível. Para isso, utiliza-se do arado reversível de três discos, permitindo a captação da água de chuva na parte do solo que não foi mobilizada pelo arado. É um sistema semipermanente, com duração de dois a três anos, também podendo ser manejado a cada cultivo, utilizando-se de arado de aiveca a tração animal. Com esse procedimento, mobiliza-se apenas a zona de plantio, cortando-se uma leiva de aração e jogando-se o solo para dentro do sulco, depois arando em sentido oposto, isto é, direcionando-se a leiva para o lado do camalhão e, assim, está efetuado o preparo para o cultivo subseqüente (ANJOS et al., 2000).

O sulco barrado é outro método de captação de água de chuva in situ. Foi desenvolvido pela Embrapa Semi-Árido e consiste de uma aração seguida de sulcamento no espaçamento exigido pela cultura. Na etapa seguinte, utiliza-se de implemento denominado "barrador de sulcos" para fazer as pequenas barreiras, que devem ficar de 2 a $3 \mathrm{~m}$ uma da outra, na linha de plantio, sendo o controle das distâncias entre as barreiras feito pelo operador do implemento. As barreiras dentro do sulco têm a finalidade de impedir o escoamento da água de chuva e promover maior infiltração, podendo ser confeccionadas antes ou depois de o cultivo ser implantado. A simplicidade do barrador de sulco e seu baixo custo viabilizam a adoção dessa técnica pelos pequenos agricultores do semi-árido brasileiro (ANJOS et al., 2000).

Neste estudo, a cultura avaliada foi o milho BR catingueiro, cujo ciclo produtivo é precoce, atingindo a maturidade dos grãos aos 90 dias após a semeadura, que foi realizada em covas, no espaçamento de 1,0 $\mathrm{m} \times$ 0,4 m, com cinco sementes por cova. Após a germinação das sementes, foi realizado o desbaste, deixando-se apenas duas plantas por cova. As parcelas experimentais foram delimitadas com dimensões de 10,0 $\mathrm{m}$ x 5,0 m, e os sulcos abertos em curva de nível, como também efetuadas as linhas de plantio com os sistemas da aração e plantio tradicional. A área experimental apresenta declividade em torno de $0,5 \%$.

Para cada evento de precipitação, a água e o solo arrastados foram coletados em caixas com capacidade de $1,0 \mathrm{~m}^{3}$, colocadas à jusante de cada tratamento (Figura 1). Ao término das chuvas, esse material foi transportado para baldes plásticos e deixado em repouso por $24 \mathrm{~h}$ para o solo sedimentar e medir a água excedente, em litros (L). Após esse tempo, o solo úmido foi levado à estufa $\left(105^{\circ} \mathrm{C}\right)$ por mais $24 \mathrm{~h}$, sendo determinada sua massa seca $(\mathrm{kg})$, de acordo com metodologia 
recomendada pela CLAESSEN (1997). Para a quantificação da precipitação ocorrida na área de estudo, foi instalado um pluviômetro, cujas leituras foram transformadas em volume de água (L) em cada tratamento; o volume de água infiltrado $\left(\mathrm{V}_{\mathrm{INF}}\right)$ foi estimado considerando a diferença entre os volumes precipitado $\left(\mathrm{V}_{\mathrm{PREC}}\right)$ e o escoado $\left(\mathrm{V}_{\mathrm{ESC}}\right)$.

O monitoramento da umidade do solo na área de plantio ocorreu efetuando-se amostragens do solo, em número de três repetições para cada tratamento, utilizando o método gravimétrico (padrão de estufa), nas profundidades $0-0,2 ; 0,2-0,4 ; 0,4-0,6 ; 0,6-0,8$ e $0,8-1,0 \mathrm{~m}$, nas diferentes fases de desenvolvimento da cultura do milho, que corresponderam às épocas de semeadura, germinação, floração e formação de espigas.

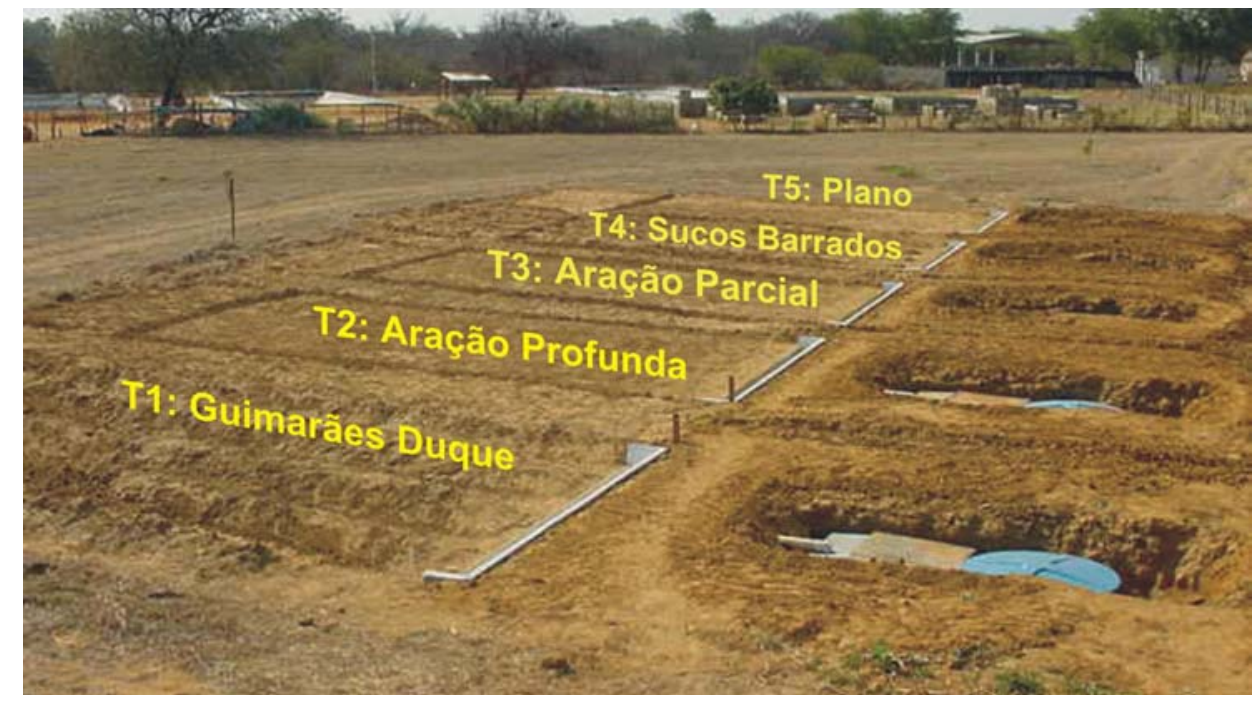

FIGURA 1. Detalhes da área de plantio e do sistema de coleta da água e do solo nos tratamentos. Details of the planting area and of water and soil collecting system in the treatments.

Em relação à planta, foram avaliados altura da planta, diâmetro do caule no nível do solo, número de espigas por planta, fitomassa verde, matéria seca e produtividade de grãos. A massa da matéria seca foi obtida a partir de amostragem ao acaso de 25 plantas por tratamento. As plantas foram secas em estufa à temperatura de $60-70^{\circ} \mathrm{C}$, até atingir peso constante. Para a avaliação da produtividade de grãos, foram colhidas as espigas de cada tratamento, retirados os grãos e pesados, sendo os dados transformados em $\mathrm{kg} \mathrm{ha}^{-1}$ (13\% base úmida). Os dados de produtividade foram avaliados por meio da análise de variância, e as médias foram comparadas por meio do teste de Tukey, a 5\% de significância.

\section{RESULTADOS E DISCUSSÃO}

Na Figura 2, apresenta-se a distribuição temporal das precipitações pluviométricas ocorridas na área experimental, nas diferentes fases fenológicas do ciclo de produção do milho, abrangendo o período da semeadura (14-2) à colheita (17-5). Observa-se que os maiores valores de precipitação ocorreram nas fases de germinação e de floração-formação de espigas, quando a cultura necessita de mais água para expressar seu potencial produtivo; a precipitação total no ciclo da cultura foi de apenas 322,8 mm. Segundo DOORENBOS \& KASSAN (1979), a quantidade de água necessária durante o ciclo produtivo da cultura do milho varia de $500-800 \mathrm{~mm}$. A deficiência de umidade no solo durante o ciclo de cultivo pode afetar gravemente o rendimento da cultura, especialmente se essa deficiência ocorre no início e durante a fase de floração.

A partir dos resultados apresentados na Figura 2 e na Tabela 2, pode-se observar que, com $27 \mathrm{~mm}$ de precipitação ocorrida em 13 de fevereiro, com duração de tempo média de 35 minutos, não houve escoamento de água e perda de solo em nenhum tratamento, isto é, toda a água se infiltrou. Isso se deve ao fato de o solo encontrar-se seco, em virtude de não ter ocorrido até então chuva na área do experimento. Entretanto, no dia seguinte à semeadura (14-2), ocorreu uma chuva 
de $43 \mathrm{~mm}$, durante 35 minutos, em média, provocando escoamento de água e perda de solo nos tratamentos $\mathrm{T} 1\left(\mathrm{~V}_{\mathrm{ESC}}=838 \mathrm{~L} ; 316 \mathrm{~kg} \mathrm{ha}^{-1}\right) ; \mathrm{T} 2\left(\mathrm{~V}_{\mathrm{ESC}}=378 \mathrm{~L} ; 109 \mathrm{~kg} \mathrm{ha}^{-1}\right)$; T3 $\left(\mathrm{V}_{\mathrm{ESC}}=478 \mathrm{~L}\right.$; $\left.69 \mathrm{~kg} \mathrm{ha}^{-1}\right)$ e T5 ( $\left.\mathrm{V}_{\mathrm{ESC}}=971 \mathrm{~L} ; 171 \mathrm{~kg} \mathrm{ha}^{-1}\right)$, enquanto no T4 (sulcos barrados) não houve escoamento superficial, significando que toda a água da chuva se infiltrou e, conseqüentemente, não houve perda de solo.

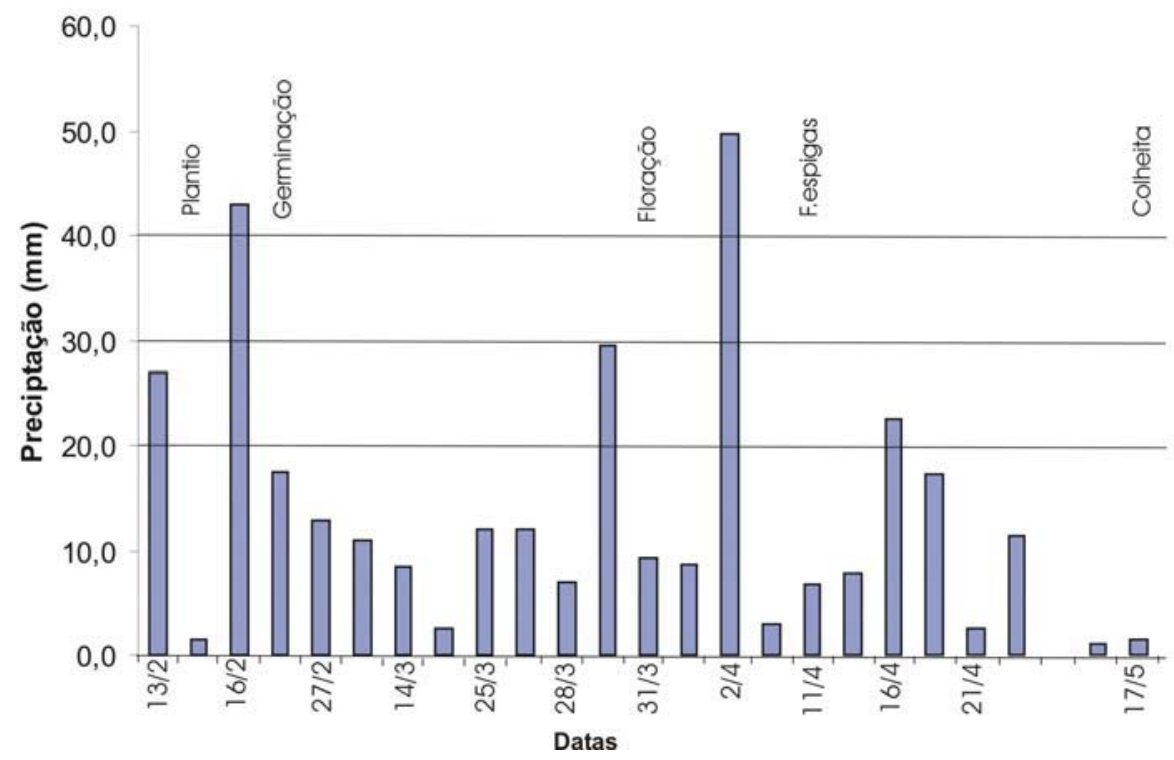

FIGURA 2. Distribuição temporal das precipitações pluviométricas na área experimental e as fases de desenvolvimento da cultura do milho. Temporal distribution of pluviometric precipitations in the experimental area and the development phases of corn crop.

TABELA 2. Volume de água escoado $\left(\mathrm{V}_{\mathrm{ESC}}\right)(\mathrm{L})$ e perda de solo $\left(\mathrm{P}_{\mathrm{SOLO}}\right)\left(\mathrm{kg} \mathrm{ha}^{-1}\right)$, em função da precipitação ( $\mathrm{V}_{\mathrm{PREC}}$, em litros (L) e dos diferentes tratamentos (T) na cultura do milho. Volume of drained water (V_ESC) (L) and soil loss (P_SOLO) $\left(\mathrm{kg}_{-} \mathrm{ha}^{-1}\right)$ as a function of the precipitation $\left(\mathrm{V} \_\right.$PREC) in liters $(\mathrm{L})$ and of the different treatments $(T)$ in the corn crop.

\begin{tabular}{|c|c|c|c|c|c|c|c|c|c|c|c|c|c|}
\hline \multirow[b]{2}{*}{ Data } & \multicolumn{3}{|c|}{ Duração } & \multicolumn{2}{|c|}{ T 1} & \multicolumn{2}{|c|}{ T 2} & \multicolumn{2}{|c|}{ Т 3} & \multicolumn{2}{|c|}{ T 4} & \multicolumn{2}{|c|}{ T 5} \\
\hline & $\begin{array}{c}\mathrm{P} \\
(\mathrm{mm})\end{array}$ & $\begin{array}{c}\text { da } \\
\text { Chuva } \\
\text { (min) }\end{array}$ & $\begin{array}{c}\mathrm{V}_{\text {PREC }} \\
\text { (L) }\end{array}$ & $\begin{array}{c}\mathrm{V}_{\mathrm{ESC}} \\
(\mathrm{L})\end{array}$ & $\begin{array}{c}\mathrm{P}_{\text {SOLO }} \\
\left(\mathrm{kg} \mathrm{ha}^{-1}\right)\end{array}$ & $\begin{array}{c}\mathrm{V}_{\mathrm{ESC}} \\
(\mathrm{L})\end{array}$ & $\begin{array}{c}\mathrm{P}_{\text {SOLO }} \\
\left(\mathrm{kg} \mathrm{ha}^{-1}\right)\end{array}$ & $\begin{array}{l}\mathrm{V}_{\mathrm{ESC}} \\
(\mathrm{L})\end{array}$ & $\begin{array}{c}\mathrm{P}_{\text {SOLO }} \\
\left(\mathrm{kg} \mathrm{ha}^{-1}\right)\end{array}$ & $\begin{array}{c}\mathrm{V}_{\mathrm{ESC}} \\
(\mathrm{L})\end{array}$ & $\begin{array}{c}\mathrm{P}_{\text {SOLO }} \\
\left(\mathrm{kg} \mathrm{ha}^{-1}\right)\end{array}$ & $\begin{array}{l}\mathrm{V}_{\mathrm{ESC}} \\
(\mathrm{L})\end{array}$ & $\begin{array}{c}\mathrm{P}_{\text {SOLO }} \\
\left(\mathrm{kg} \mathrm{ha}^{-1}\right)\end{array}$ \\
\hline 13-fev. & 27,0 & 35 & 1.350 & 0,0 & 0,0 & 0,0 & 0,0 & 0,0 & 0,0 & 0,0 & 0,0 & 0,0 & $\overline{0,0}$ \\
\hline 14-fev. & 1,4 & 10 & 70 & 0,0 & 0,0 & 0,0 & 0,0 & 0,0 & 0,0 & 0,0 & 0,0 & 0,0 & 0,0 \\
\hline 16-fev. & 43,0 & 35 & 2.150 & 838 & 316,0 & 378 & 109,0 & 478 & 69,0 & 0,0 & 0,0 & 971 & 171 \\
\hline 19-fev. & 17,5 & 30 & 875 & 180 & 101,0 & 87 & 13,0 & 98 & 28,0 & 0,0 & 0,0 & 108 & 25 \\
\hline 27-fev. & 12,8 & 25 & 640 & 161 & 247,0 & 82 & 149,0 & 28 & 11,0 & 0,0 & 0,0 & 32 & 4,0 \\
\hline 10-mar. & 11,0 & 20 & 550 & 41 & 13,0 & 40 & 12,0 & 23,5 & 12,0 & 26 & 12,0 & 29 & 11,0 \\
\hline 14-mar. & 8,4 & 30 & 420 & 26 & 6,0 & 22 & 8,0 & 3 & 3,0 & 0,0 & 0,0 & 17,3 & 5,0 \\
\hline 21-mar. & 2,5 & 15 & 125 & 0,0 & 0,0 & 0,0 & 0,0 & 0,0 & 0,0 & 0,0 & 0,0 & 0,0 & 0,0 \\
\hline 25-mar. & 12,0 & 150 & 600 & 143 & 104,0 & 83 & 13,0 & 30 & 15,0 & 0,0 & 0,0 & 35 & 9,0 \\
\hline 27-mar. & 12,0 & 75 & 600 & 129 & 97,0 & 77 & 11,0 & 28 & 13,0 & 0,0 & 0,0 & 33 & 8,0 \\
\hline 28-mar. & 7,0 & 45 & 350 & 87 & 29,0 & 64 & 7,0 & 14 & 3,0 & 0,0 & 0,0 & 28 & 4,0 \\
\hline 29-mar. & 29,5 & 75 & 1.475 & 1.080 & 513,0 & 460 & 120,0 & 600 & 69,0 & 420 & 64,0 & 680 & 208 \\
\hline 31-mar. & 9,3 & 30 & 465 & 80 & 90,0 & 24 & 13,0 & 34 & 37,0 & 0,0 & 0,0 & 12 & 16,0 \\
\hline $1^{\mathrm{o}}$-abr. & 8,6 & 35 & 430 & 60 & 66,0 & 48 & 28,0 & 30 & 33,0 & 0,0 & 0,0 & 18 & 25,0 \\
\hline 2-abr. & 49,7 & 85 & 2.485 & 2.250 & 10.489 & 874 & 2.904 & 1.127 & 1.918 & 620 & 946 & 1.840 & 4.196 \\
\hline 4-abr. & 3,0 & 20 & 150 & 0,0 & 0,0 & 0,0 & 0,0 & 0,0 & 0,0 & 0,0 & 0,0 & 0,0 & 0,0 \\
\hline 11-abr. & 6,8 & 40 & 340 & 0,0 & 0,0 & 0,0 & 0,0 & 0,0 & 0,0 & 0,0 & 0,0 & 0,0 & 0,0 \\
\hline 14-abr. & 7,7 & 20 & 385 & 0,0 & 0,0 & 0,0 & 0,0 & 0,0 & 0,0 & 0,0 & 0,0 & 0,0 & 0,0 \\
\hline 16-abr. & 22,5 & 60 & 1.125 & 648 & 2.083 & 512 & 340,0 & 600 & 25,0 & 0,0 & 0,0 & 840 & 272,0 \\
\hline 19-abr. & 17,3 & 225 & 865 & 216 & 543,0 & 132 & 265,0 & 156 & 293,0 & 0,0 & 0,0 & 132 & 34,0 \\
\hline 21-abr. & 2,5 & 30 & 125 & 0,0 & 0,0 & 0,0 & 0,0 & 0,0 & 0,0 & 0,0 & 0,0 & 0,0 & 0,0 \\
\hline 26-abr. & 11,3 & 60 & 565 & 150 & 528 & 93 & 18,0 & 36 & 18,0 & 0,0 & 0,0 & 36 & 11,0 \\
\hline Total & 322,8 & - & 1.6140 & 6.089 & 15.225 & 2.976 & 4.010 & $3.285,5$ & 2.547 & 1.066 & 1.022 & 4.811 & 4.999 \\
\hline
\end{tabular}

T1 - Guimarães Duque; T2 - aração profunda; T3 - aração parcial; T4 - sulcos barrados, e T5 - sistema tradicional. 
Nas Figuras 3a-d, apresentam-se os quatro tipos de preparo do solo efetuados na área de estudo explorada com a cultura do milho, após a ocorrência de chuva de 29,5 mm (29-3), que proporcionou acúmulo de água no solo nos tratamentos T1 (Guimarães Duque), T4 (sulcos barrados) e no T5 (sistema tradicional). Desses, nos tratamentos T1 e T5, ocorreram maior volume de água escoado, conseqüentemente, menor volume infiltrado; por outro lado, nos tratamentos T2, T3 e T4, ocorreu maior infiltração, gerando maior teor de água no solo disponível para a cultura.

a. Sistema Guimarães Duque (T1).

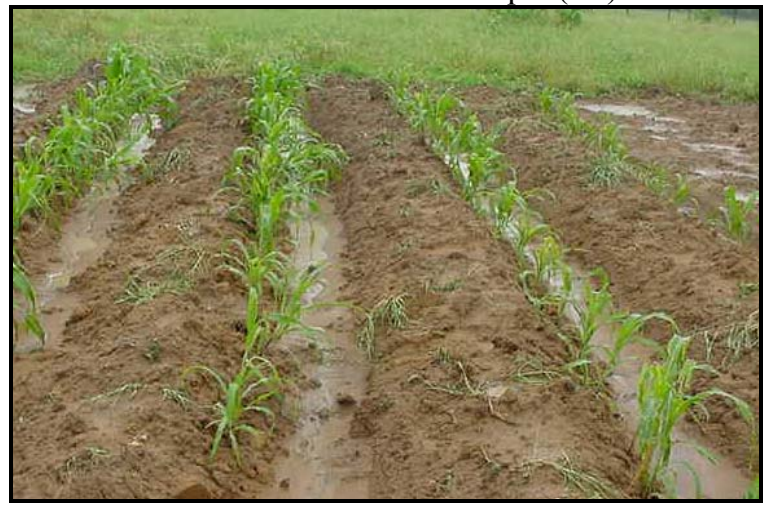

c. Sistema com aração parcial (T3).

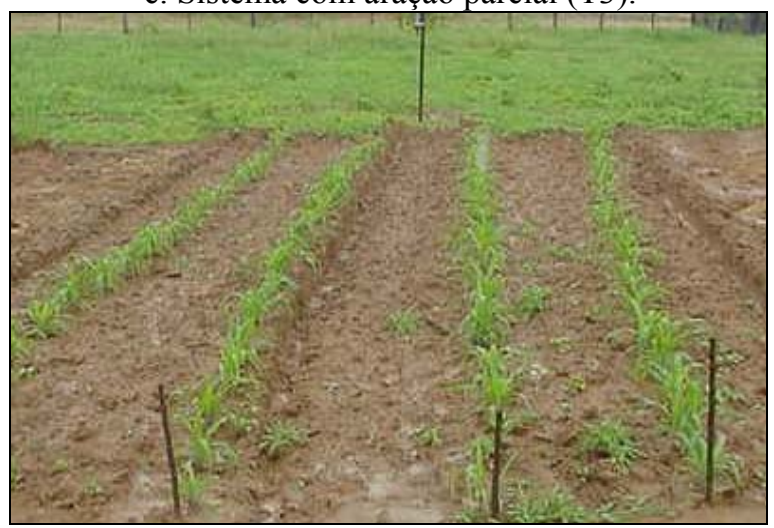

b. Sulcos barrados (T4)

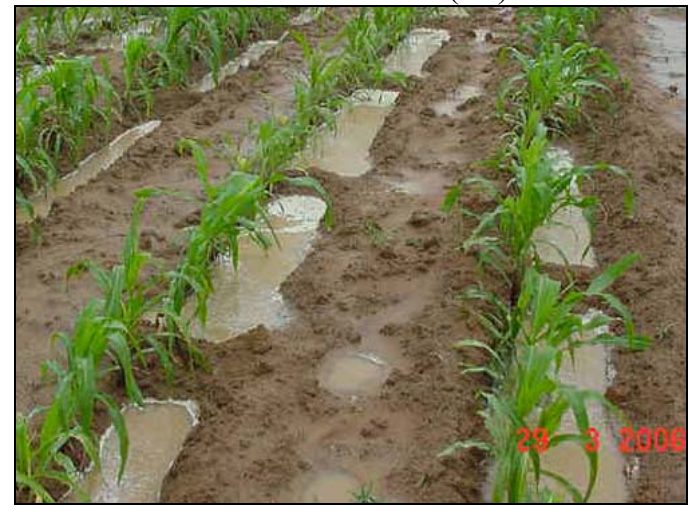

d. Sistema tradicional de plantio (T5).

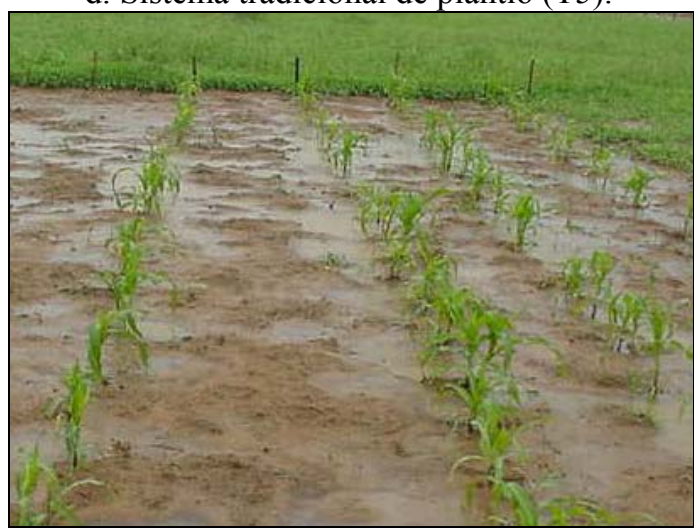

FIGURA 3. Métodos de captação de água de chuva in situ. In situ rainwater harvesting methods.

Observando a Tabela 2, verifica-se que o mês com maior precipitação foi abril, com o total de $129,4 \mathrm{~mm}$, dos quais 49,7 $\mathrm{mm}(38,41 \%)$ ocorreram em apenas um dia (2-4), sendo 19,2 mm no decorrer de 40 minutos, e $30,5 \mathrm{~mm}$ em 45 minutos, nas fases de floração-formação de espigas, proporcionando perdas de água e de solo em todos os tratamentos, com maiores valores no tratamento T1 $\left(2.250 \mathrm{~L} ; 10.489 \mathrm{~kg} \mathrm{ha}^{-1}\right)$ e na testemunha T5 $\left(1.840 \mathrm{~L} ; 4.196 \mathrm{~kg} \mathrm{ha}^{-1}\right)$. No tratamento $\mathrm{T} 4$, as perdas de água e de solo foram de apenas $620 \mathrm{~L} \mathrm{e} 946 \mathrm{~kg} \mathrm{ha}^{-1}$, respectivamente. A tendência de o comportamento do T4 apresentar menores valores de perdas de solo foi observada em todos os eventos de chuva; isso se deve ao fato de as barreiras formadas nos sulcos das linhas de plantio impedirem o escoamento da água, favorecendo maior infiltração e, conseqüentemente, menores perdas de água e de solos. Esse sistema, portanto, constitui-se no melhor tipo de preparo do solo para a cultura do milho nas condições edafoclimáticas analisadas.

Esses resultados corroboram SILVA et al. (1999), que obtiveram as maiores perdas de água e de solo em áreas aradas e gradeadas. Esses autores analisaram 20 anos de precipitação, correlacionando-a com o escoamento superficial e observaram que áreas com uma e duas arações e gradagem proporcionaram aumentos nas perdas de água na ordem de 2,5 e 2,6 vezes, e de solos na ordem de 4,2 a 7,4 vezes, comparadas às áreas com tratamento tradicional (cultivadas com enxada), respectivamente. 
(a) Umidade do solo (\%)

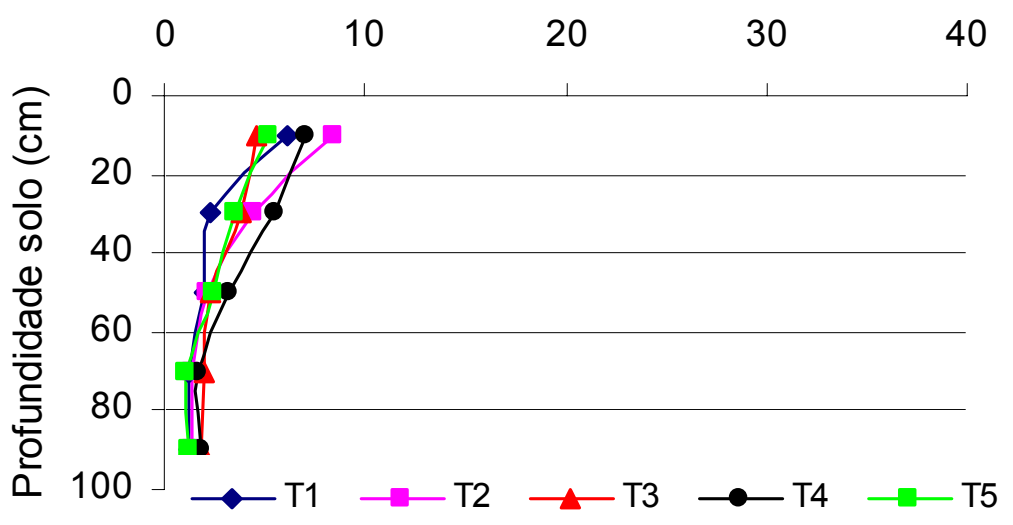

(b) Umidade do solo (\%)

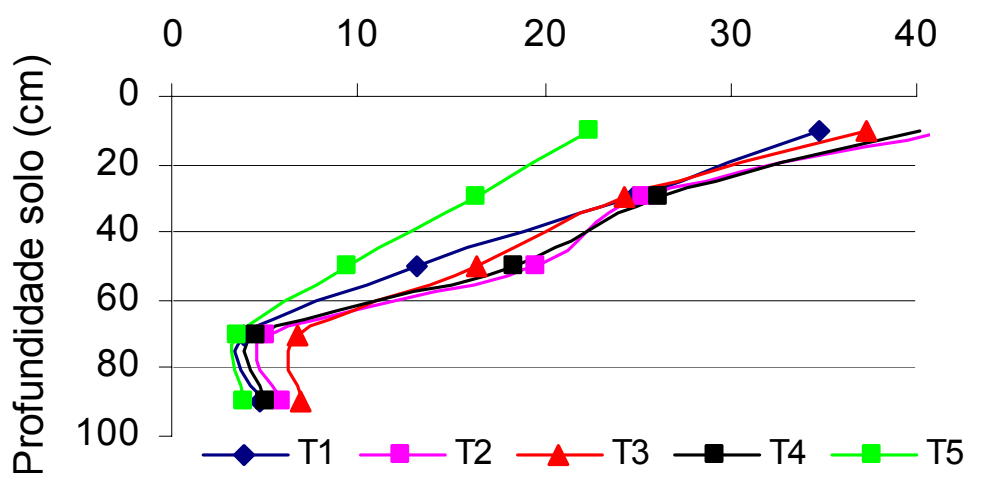

(c) Umidade do solo (\%)

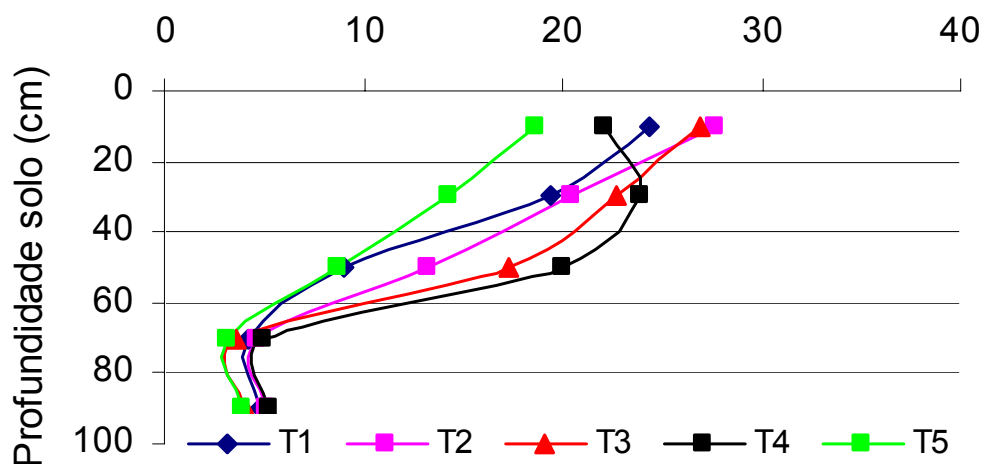

(d) Umidade do solo (\%)

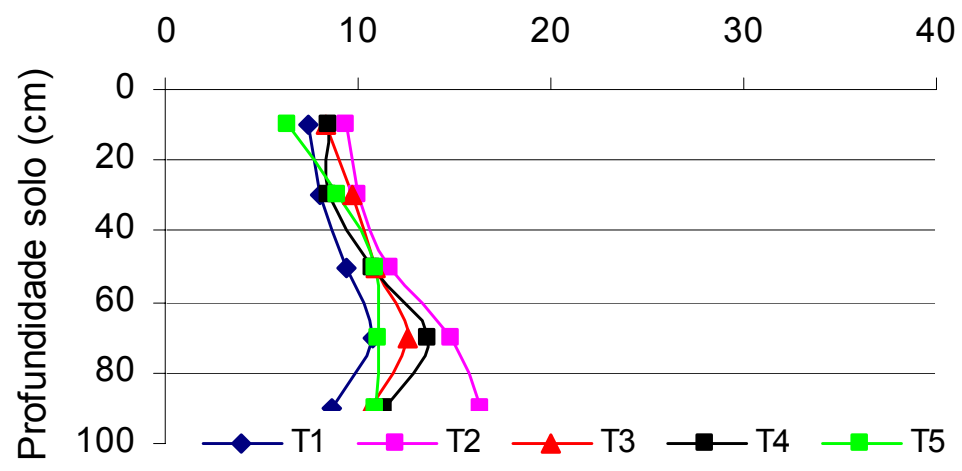

FIGURA 4. Variação da umidade do solo em função dos tratamentos e nas diferentes fases de cultivo: semeadura (a), germinação (b), floração (c) e formação de espigas (d). Soil moisture variation as a function of the treatments and in the different growing phases, planting (a), germination (b) flowering (c) and ear of corn formation (d). 
O monitoramento da umidade do solo foi efetuado nas diferentes fases do ciclo de produção do milho, correspondendo à semeadura, germinação, floração e formação de espigas, apresentadas na Figuras 4a-d, respectivamente. Observa-se que, no momento da semeadura (Figura 4a), a umidade inicial do solo apresentou baixos valores ao ponto de murcha permanente em todo o perfil, devido às baixas precipitações ocorridas na área experimental. Os maiores valores de umidade nessa fase foram obtidos nos tratamentos T2 $(8,38 \%)$ e T4 $(7,11 \%)$. Esses resultados estão relacionados com o maior volume de água infiltrado, proporcionado pela aração profunda e pelo sulco barrado, conseqüentemente, maior disponibilidade de umidade do solo nesta fase da cultura. Essa mesma tendência foi observada em todas as fases de desenvolvimento da cultura e em todas as profundidades do solo. O T5 (sistema tradicional) apresentou menores valores de umidade do solo.

Na Tabela 3, apresentam-se as características como altura de planta, diâmetro basal, número de espigas, matéria seca e produtividade de grãos $\left(\mathrm{kg} \mathrm{ha}^{-1}\right)$ obtidas na cultura do milho, nos diferentes tratamentos. Pode-se observar que a maior produtividade de grãos $\left(606 \mathrm{~kg} \mathrm{ha}^{-1}\right)$ e de matéria seca $\left(482,0 \mathrm{~kg} \mathrm{ha}^{-1}\right)$ foi obtida no sistema do sulco barrado (T4), seguido pelos tratamentos T3 (370 kg ha $\left.{ }^{-1}\right)$ e T2 (362 $\left.\mathrm{kg} \mathrm{ha}^{-1}\right)$, que não apresentaram diferença significativa pela análise de variância. Os maiores valores de produtividade nesses tratamentos estão diretamente relacionados com a maior disponibilidade de água no solo no período da floração, quando há maior demanda de água pela cultura do milho. Nessa fase, a umidade do solo estava em torno de $20 \%$ e $17 \%$ nas profundidades de $40 \mathrm{~cm}$ a $60 \mathrm{~cm}$, respectivamente. A menor produtividade de grãos, aproximadamente $50 \%$ da maior, foi obtida no sitema tradicional (T5), correspondendo a $302 \mathrm{~kg} \mathrm{ha}^{-1}$. Quanto às demais características analisadas, observa-se que o sistema tradicional (T5) apresentou diferença estatística entre os demais tratamentos para todas as variáveis, com exceção do número de espigas.

Embora esses valores de produtividade de grãos da cultura do milho sejam considerados baixos, comparados com os resultados citados por WENDLING et al. (2002) e SUZUKI \& ALVES (2004), deve-se ressaltar que, nas condições deste estudo, é um resultado considerável, visto que, em 2005, a produção média de milho obtida nos Estados do Piauí, do Ceará, do Rio Grande do Norte, da Paraíba, de Pernambuco e de Alagoas foi de 661; 497; 465; 402; 560 e $475 \mathrm{~kg} \mathrm{ha}^{-1}$, respectivamente (IBGE, 2006), valores próximos da média total obtida $\left(392,4 \mathrm{~kg} \mathrm{ha}^{-1}\right)$ nesses estudos.

TABELA 3. Valores obtidos para a cultura do milho observados nos diferentes métodos de preparo de solo. Values obtained for the corn crop in the different soil preparation methods.

\begin{tabular}{lccccc}
\hline \multicolumn{1}{c}{ Tratamentos } & $\begin{array}{c}\text { Altura } \\
(\mathrm{m})\end{array}$ & $\begin{array}{c}\text { Diâmetro } \\
\text { Basal }(\mathrm{m})\end{array}$ & $\begin{array}{c}\text { Número de } \\
\text { Espigas }\end{array}$ & $\begin{array}{c}\text { Matéria Seca } \\
\left(\mathrm{kg} \mathrm{ha}^{-1}\right)\end{array}$ & $\begin{array}{c}\text { Produtividade } \\
\left(\mathrm{kg} \mathrm{ha}^{-1}\right)\end{array}$ \\
\hline T1 - Guimarães Duque & $1,42 \mathrm{a}$ & $0,95 \mathrm{a}$ & $1,03 \mathrm{a}$ & $306,0 \mathrm{c}$ & $322,0 \mathrm{c}$ \\
T2 - Aração profunda & $1,55 \mathrm{a}$ & $1,14 \mathrm{a}$ & $1,01 \mathrm{a}$ & $346,0 \mathrm{~b}$ & $362,0 \mathrm{~b}$ \\
T3 - Aração parcial & $1,51 \mathrm{a}$ & $1,04 \mathrm{a}$ & $1,03 \mathrm{a}$ & $376,0 \mathrm{~b}$ & $370,0 \mathrm{~b}$ \\
T4 - Sulco barrado & $1,52 \mathrm{a}$ & $0,98 \mathrm{a}$ & $1,01 \mathrm{a}$ & $482,0 \mathrm{a}$ & $606,0 \mathrm{a}$ \\
T5 - Solo plano & $1,21 \mathrm{~b}$ & $0,71 \mathrm{~b}$ & $1,00 \mathrm{a}$ & $190,0 \mathrm{~d}$ & $302,0 \mathrm{~d}$ \\
\hline Média & 1,44 & 0,96 & 1,02 & 340,0 & 392,4 \\
\hline Desvio-Padrão & 13,40 & 16,40 & 4,20 & 97,51 & 100 \\
\hline
\end{tabular}

${ }^{1}$ Médias seguidas pela mesma letra nas colunas não diferem entre si, pelo Teste de Tukey, a 5\%.

\section{CONCLUSÕES}

O sistema de preparo do solo com sulcos barrados (T4), para o cultivo do milho, apresentou os menores valores de perdas de água e de solo, enquanto os maiores valores foram obtidos nos tratamentos Guimarães Duque (T1) e no sistema tradicional (T5).

A eficiência do sistema de sulcos barrados proporcionou os maiores rendimentos em termos de produtividade de grãos e de matéria seca. 
Os maiores valores de umidade do solo, para o cultivo do milho, foram obtidos com o tratamento sulcos barrados.

\section{REFERÊNCIAS}

ANJOS, J.B.; BRITO, L. T. de L.; SILVA, M.S.L. da. Métodos de captación de água de lluvia in situ e irrigación. In.: FAO. Manual de práticas integradas de manejo y conservación de suelos. Roma, 2000. cap. 15, p.139-150. (Boletín de Tierras y Águas, 8).

BERTONI, J.; LOMBARDI NETO, F. Conservação do solo. 4.ed. São Paulo: ICONE, 1999. 355 p.

CLAESSEN, M.E.C. (Org.). Manual de métodos de análise de solo. 2.ed. rev. atual. Rio de Janeiro: EMBRAPA-CNPS, 1997. 212 p. (Documentos, 1).

DOORENBOS, J.; KASSAM, A.H. Yield response to water. Roma: FAO, 1979. 193 p. (Irrigation and Drainage Paper, 33).

IBGE. INSTITUTO BRASILEIRO DE GEOGRAFIA E ESTATÍSTICA. Produção agrícola municipal 2005. Disponível em: <http://www.ibge.gov.br>. Acesso em: 5 set. 2006.

MOURA, M.S.B.; SILVA, T.G. da; BORGES, C.J.R. Análise da precipitação e do número de dias de chuva no município de Petrolina - PE. In: SIMPÓSIO BRASILEIRO DA CAPTAÇÃO E MANEJO DE ÁGUA DE CHUVA, 5., 2005, Teresina. Anais... Petrolina: Associação Brasileira de Captação de Água de Chuva, 2005. 1 CD-ROM.

PORTO, E.R.; GARAGORRY, F.L.; SILVA, A. de S.; MOITA, A.W. Risco climático: estimativa de sucesso da agricultura dependente de chuva para diferentes épocas de plantio I. Cultivo do feijão (Phaseolus vulgaris L.). Petrolina: EMBRAPA-CPATSA, 1983. 129 p. (Documentos, 23)

SANTOS, H.G. dos; JACOMINE, P.K.T.; ANJOS, L.H.C. dos; OLIVEIRA, V.A. de; OLIVEIRA, J.B. de; COELHO, M.R.; LUMBRERAS, J.F.; CUNHA, T.J.F. (Ed.). Sistema brasileiro de classificação de solos. 2.ed. Rio de Janeiro: Embrapa Solos, 2006. 306 p.

SILVA, A.B.; RESENDE, M.; SOUSA, A.R.; MARGOLIS, E. Mobilização do solo, erosão e produtividade de milho e feijão em um regossolo no agreste pernambucano. Pesquisa Agropecuária Brasileira, Brasília, v.34, n.2, p.299-307, 1999.

SILVA, A. de S.; PORTO, E.R. Utilização e conservação dos recursos hídricos em áreas rurais do Trópico Semi-Árido do Brasil: tecnologias de baixo custo. Petrolina: EMBRAPA-CPATSA, 1982. 128 p. (Documentos, 14).

SUZUKI, L.E.A.S.; ALVES, M.C. Produtividade do milho (Zea mays L.) influenciada pelo preparo do solo e por plantas de cobertura em Latossolo Vermelho. Acta Scientiarum, Maringá, v.26, n.1, p.61-5, 2004.

WENDLING, A.; ELTZ, F.L.F.; DIDONÉ JÚNIOR, A.; COGO, C.M.; SANTOS, M.V.C.; BECKER, M.W. Produtividade de grãos e massa seca de milho sob plantio direto no período de 1998-2002. In: REUNIÃO BRASILEIRA DE MANEJO E CONSERVAÇÃO DO SOLO E DA ÁGUA, 14., 2002, Cuiabá. Anais... Cuiabá: Sociedade Brasileira de Ciência do Solo, 2002. 1 CDROM. 